\title{
Influence of surface treatment on the wetting process of jute fibres with thermosetting polyester resin
}

\author{
Aleksandra Bogdan-Włodek, Mateusz Kozioł", Jerzy Myalski \\ Silesian University of Technology, Faculty of Materials Engineering and Metallurgy, ul. Krasińskiego 8, 40-019 Katowice, Poland \\ Corresponding author: e-mail: Mateusz.Koziol@polsl.pl
}

\begin{abstract}
The aim of this study is the evaluation of the effect of chemical treatment of jute fibres on their permeability with polyester resin and determination of optimal treatment parameters. Unmodified jute fabric by LENTEX, Poland and polyester resin ESTROMAL 14 were used in the experiments. $\mathrm{NaOH}$ and $\mathrm{KOH}$ water solutions (various concentration - from 1 to $15 \%$ - and treatment duration - from 0.5 to $6 \mathrm{~h}$ ), vinyl acetate, methanol, toluene diizocyanate were used for the treatment. Determination of the effect of the chemical treatment on fiber-resin interaction was made in: infiltration of resin into reinforcement structure tests and fabric absorbability tests. Three criteria: time of penetration of resin into the reinforcing fabric, fabric absorbability and the area of a part of the specimen cross-section penetrated with the resin were taken into account. The fabrics treated with 1-5\% - long-time and 15\% short-time $\mathrm{NaOH}$ and $\mathrm{KOH}$ water solutions showed the best results within the tested criteria. These results do not correspondent directly with the mechanical properties of cured composites manufactured on the base of the treated fabrics. Alkali- and organic treatments significantly improve the mechanical performance of natural fibres reinforced composites, but organic treatments (methanol, toluene diisocyanate) gives better improvement in mechanical properties in comparison with the alkali-treatments. The measurement methods applied in the study may be generally useful in the evaluation of the effect of chemical treatment of natural fibres on their wettability with the liquid matrix.
\end{abstract}

Keywords: natural fibres, jute fibres, surface treatment, wetting prosess, fibre reinforced composites.

\section{INTRODUCTION}

Currently, the vital application of vegetable natural fibres consists in using them as the reinforcing components in polymer-matrix composite materials. Replacement of the mineral fibres (glass, carbon) with natural fibres in certain uses gives saving (up to $30 \%$ ) in the production cost and in product weight ${ }^{1-3}$.

The main problems of natural fibres concerning composite materials technology are: low adhesion between the fibre and liquid polymer, low dimensional stability, low thermal resistance, high higroscopicity and high flammability. Improvement in these properties may be achieved by fibre surface treatment using physical or chemical methods ${ }^{2-4}$. The physical methods, which contain among others: positioning by stretching, calendering, crown discharges treatment do not change the chemical structure of the fibre and consist mainly in the production of increase in free surface energy on the fibre-liquid interface. On the other hand, chemical methods consist most often in the production of new chemical compounds in the near-surface area, acting as the coupling agents between the fibres and liquid matrix. Chemical treatment processes may also lead to the transformation of original cellulose into type II cellulose and to decrease in average twist angle of microfibrils due to internal structural stresses arisen during chemical reactions ${ }^{5,6}$. The chemical methods include among others graft copolymerization (methyl methacrylate, vinyl acetate, styrene, acrylonitrile) and application of the end-use finishes as silanes or toluene diizocyanate ${ }^{7,8}$.

Basing on literature analysis it was found that natural fibres, due to their specific properties, may become a substitute of the mineral fibres in some application areas if the problem of their low wettability with the liquid polymer matrix is resolved. The aim of this study is the evaluation of the effect of chemical treatment of jute fibres on their permeability with polyester resin and determination of treatment process parameters and therefore - obtain the jute fibre showing good wettability with a resin.

\section{EXPERIMENTAL}

\section{Materials}

Unmodified plain-weave jute fabric produced by Lentex Pabianice, Poland, was used in the experiments. Areal weight of the fabric is $350 \mathrm{~g} / \mathrm{m}^{2}$. Avaerage yarn density within the fabric is 288 tex.

According to previous literature information ${ }^{4,5,9}$, the following substances have been selected for accomplishing the treatment: $\mathrm{NaOH}$ and $\mathrm{KOH}$ water solutions (various concentration and treatment duration), vinyl acetate, methanol, toluene diizocyanate. Concentration of the $\mathrm{NaOH}$ and $\mathrm{KOH}$ solutions was: $1,3,5,15 \%$. The treatment duration was: $0.5,1,2,4,6 \mathrm{~h}$. The treatment processes were carried out at room temperature.

After alkali-treatment the fabric sheets were washed in distilled water, neutralized in $1 \% \mathrm{HCl}$ water solution, and secondary washed. Next to this procedure the sheets were exsiccated in $40^{\circ} \mathrm{C}$ by $24 \mathrm{~h}$.

Treatment with the use of methanol and vinyl acetate included 30-min long immersion and following exsiccation in $30^{\circ} \mathrm{C}$ by $24 \mathrm{~h}$. Treatment with toluene diizocyanate included 30-min long immersion with next exsiccation in $25^{\circ} \mathrm{C}$ by $24 \mathrm{~h}$. Such treatment process was to help in the determination of optimal parameters, assuring possibly the best coupling properties in the fibre-resin interface. The investigations were carried out with the use of ESTROMAL 14-LM 03 polyester resin by ERG Pustkow, Poland. Luperox (solution of methylethylketone 
peroxide in dibutyl phthalate) was used as a catalyst in the amount of $1.5 \%$ by weight.

\section{Measurements}

Determination of the effect of chemical treatment on fiber-resin interaction was made in: infiltration of resin into reinforcement structure tests and fabric absorbability tests. The tests were conducted using the individually designed work-stands (Fig.1).

Evaluation of the area penetrated with the resin was carried out on the specimens being "stacks" of 2050 x $50 \mathrm{~mm}$ fabric sheet layers laid up one by one. They were put between two steel plates ("mold"). The upper plate had a hole being an outlet of special "stack", filled with the exact amount $\left(3 \mathrm{~cm}^{3}\right)$ of the resin with an addition of the curing agent (Fig.1a). Such geometry (the round cross-section of the column of the resin) warrants uniform propagation of the liquid, without any privileged directions. The test consisted in the measurement of the time in which all the resin $\left(3 \mathrm{~cm}^{3}\right)$ penetrates the stack of fabric sheet layers. Pressure in the layers between two plates is constant - it is determined only by weight of the upper plate and is uniform for all the tested specimens. After curing of the resin and removal of the sheets from the "mold", the number of the layers wetted by the penetrating resin was evaluated. Afterwards, the specimens were cut along the longest diameter of the elliptic saturated "spot" on the upper (first) layer. The area of part of the cross-section penetrated with resin

a)

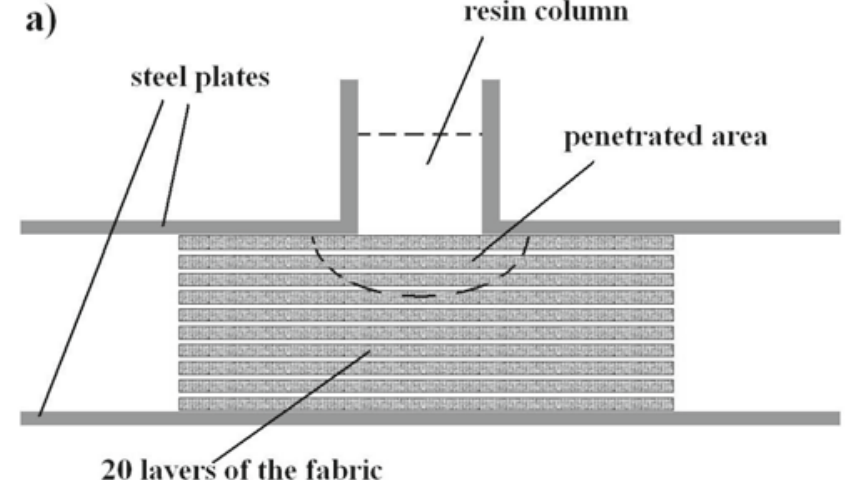

b)

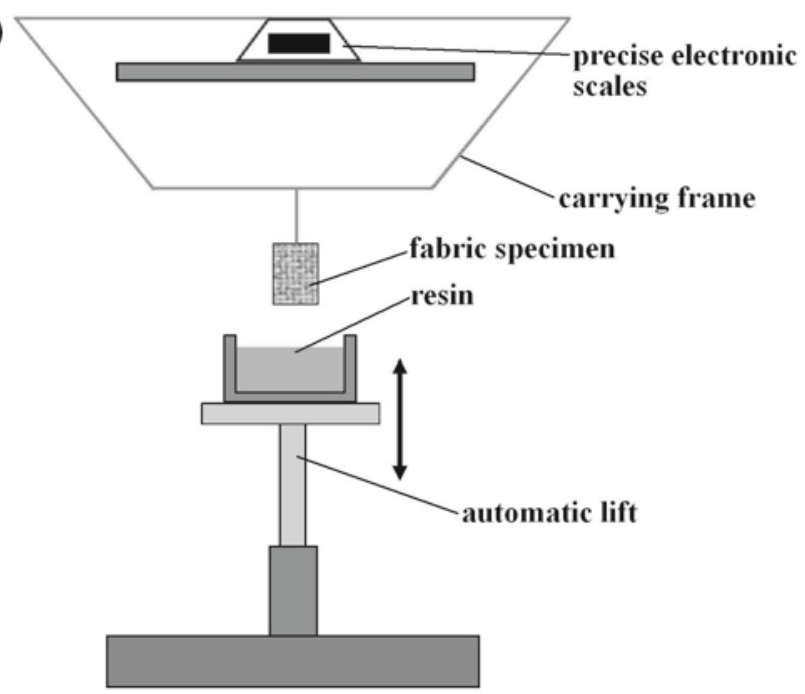

Figure 1. A scheme of the research work-stands used within the study: a) infiltration of resin into the reinforcement structure tests stand - cross-section, b) fabric absorbability tests stand was measured.

In order to determine the fabric (yarn) absorbability, the 35 x $100 \mathrm{~mm}$ strip specimens were cut. The specimens were preliminarily weighed and loaded with pieces of lead strip - it gave stable conditions of immersion in a highly viscous resin. Subsequently, the specimens were fixed to the special grips and completely immersed in the resin (Fig.1b). They remained immersed for $10 \mathrm{~s}$ and taken out. After taking the wet specimens from the resin they were secondarily weighed (the measure point was the moment the continuous stream of dripping resin lost its continuity by the first time). The measure of the fabric (yarn) absorbability is the difference in mass - after and before the immersion.

\section{RESULTS AND DISCUSSION}

An evaluation of the effect of the applied chemical treatments on the fiber-resin interaction was made on a base of three criteria (basic criteria of infiltration quality) concerning technological aspects of composite materials manufacturing process: time of a penetration of the resin into the reinforcing fabric, fabric absorbability and the part of the area of the specimen cross-section penetrated with the resin. The criteria allow to evaluate the way of spreading of the liquid matrix inside the reinforcement structure during an infiltration process. The results of the infiltration tests and fabric absorbability tests are given in Figs. 2 and 3.

Concerning the analysis of the penetration time of the resin into the reinforcing fabric, the area of the penetrated part of specimen's cross section and the mass of the resin absorbed in the fabric specimen, treatment conditions which have the most advantageous effect on the basic criteria of infiltration quality such as: the shortest penetration time, the biggest area of saturated part of specimen's cross section and the biggest mass of resin absorbed on specimen, have been indicated. Within the indicated range (Figs.2 and 3) mainly alkali-treatments of relatively long-duration and low concentration seem to be optimal. The applied treatments cause shortening of the penetration time and increase in the mass of the absorbed resin.

It was observed that treatment in $\mathrm{NaOH}$ solution and $\mathrm{KOH}$ solution as well causes increase in the mass of the absorbed resin, in comparison with the untreated fabric (average increase by 30\%). As regards the obtained results (Fig.2) it is obvious that the penetration time of the resin into the fabric is two times longer for the untreated fabric than for the treated ones. Numerous previous studies have shown that as a consequence of $\mathrm{NaOH}$ or $\mathrm{KOH}$ solutions, activity purification and surface development of fibres take place, mainly through the removal of some structural components - mainly a lignin and hemicellulose $e^{\mathbf{1 , 2 , 7 , 8}}$. Some authors found among other things that the decrease in thermal decomposition temperature of the cellulose went down from $365.26^{\circ} \mathrm{C}$ for raw jute fibre to $360.62^{\circ} \mathrm{C}$ for jute after $8 \mathrm{~h}$ of alkali treatment $(5 \% \mathrm{NaOH}$ solution) is due to the removal of hemicellulose and lignin from the structure ${ }^{5}$. After the structural changes cellulose (jute) fibres show better chemical activity and they easier interact with liquid $\operatorname{resin}^{\mathbf{1 , 2}}$. AFM adhesion force measurements on natural 


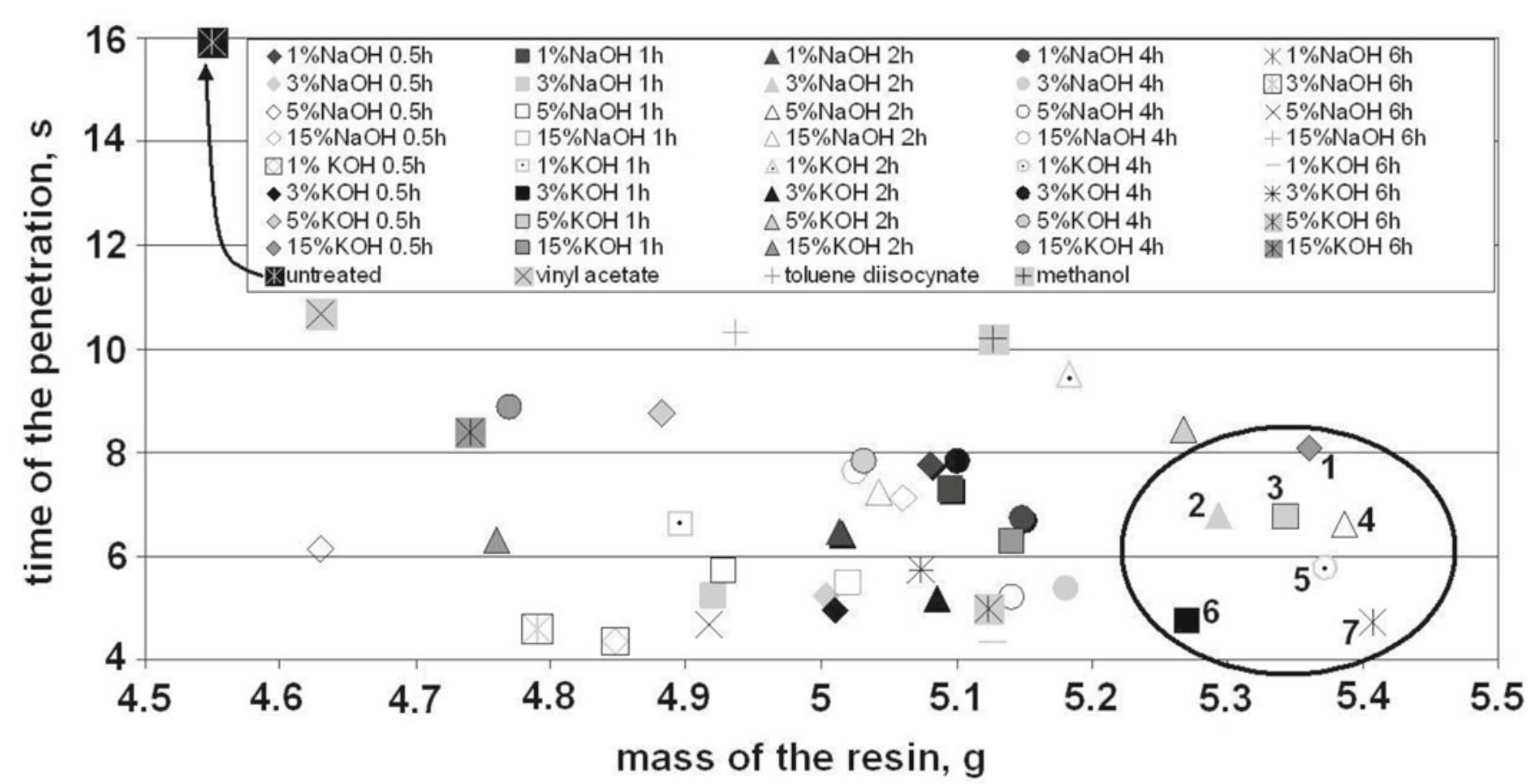

Figure 2. The effect of various chemical treatment on the penetration time of a resin into the reinforcing fabric and the mass of absorbed resin. The results promising for further processing marked: $1-15 \% \mathrm{KOH} 0.5 \mathrm{~h}, 2-3 \% \mathrm{NaOH} 2 \mathrm{~h}, 3-5 \% \mathrm{KOH}$ $1 \mathrm{~h}, 4-5 \% \mathrm{NaOH} 2 \mathrm{~h}, 5-1 \% \mathrm{KOH} 4 \mathrm{~h}, 6-3 \% \mathrm{KOH} 1 \mathrm{~h}, 7-1 \% \mathrm{NaOH} 6 \mathrm{~h}$

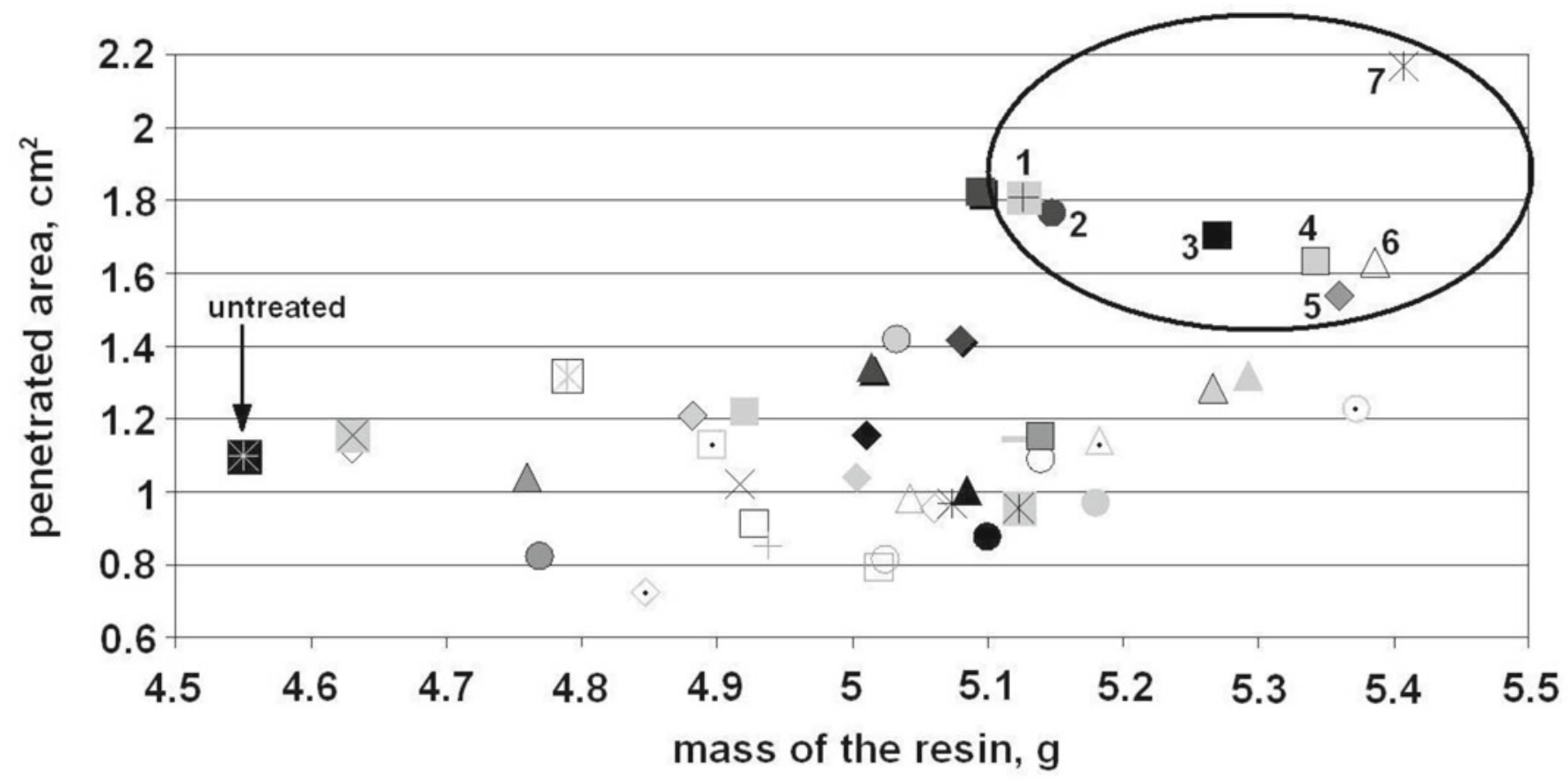

Figure 3. The effect of various chemical treatment on the area of the penetrated area of specimen's cross section and the mass of absorbed resin (key of the marks is available in the Fig.2). The results promising for further processing marked: 1 methanol, $2-1 \% \mathrm{NaOH} 4 \mathrm{~h}, 3-3 \% \mathrm{KOH} 1 \mathrm{~h}, 4-5 \% \mathrm{KOH} 1 \mathrm{~h}, 5-15 \% \mathrm{KOH} 0.5 \mathrm{~h}, 6-5 \% \mathrm{NaOH} 2 \mathrm{~h}, 7-1 \% \mathrm{NaOH} 6 \mathrm{~h}$

fibre samples have also revealed that alkali-treatment causes a significant increase in their polarity ${ }^{5}$. The shortest penetration time and the biggest mass of the absorbed resin were obtained after the treatment in alkali-solutions of low concentration $(1,3,5 \%)$ by the relatively low treatment duration. Similar effects may be obtained using the $15 \% \mathrm{KOH}$ water solution by short treatment duration.

The best results in the penetration time and the mass of the absorbed resin were obtained for the fabric sheets after: $1 \% \mathrm{NaOH} 6 \mathrm{~h}, 5 \% \mathrm{NaOH} 2 \mathrm{~h}, 5 \% \mathrm{KOH}$ h and $15 \% \mathrm{KOH} 0.5 \mathrm{~h}$. Chemical treatment in the solutions of $\mathrm{NaOH}$ and $\mathrm{KOH}$ gives the improvement in the infiltration of a resin into the fabric. Shortening of the penetration time and increase in the area of the penetrated part of specimen's cross section after the treatment for most of the applied substances was observed. Analysis of the results (Fig.3) allows to claim that application of the low-concentrated solutions $(1,3,5 \%)$ contributes to the increase in the area of the penetrated part of specimen's cross section in comparison with the untreated jute (the penetrated cross-section area $=1.1 \mathrm{~cm}^{2}$ ), however, only by long treatment duration.

In Fig.4 the exemplary results of the area of the penetrated part of specimen's cross section, the penetration time and the number of layers wetted by penetrating 
a)

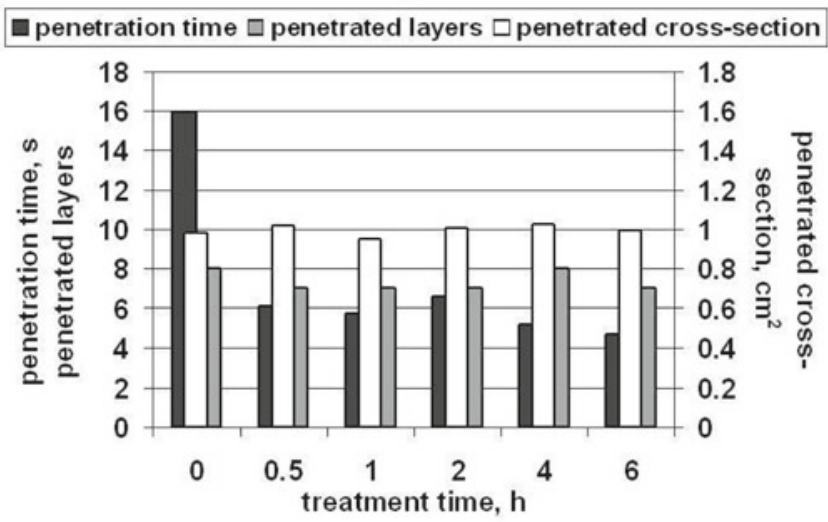

b)

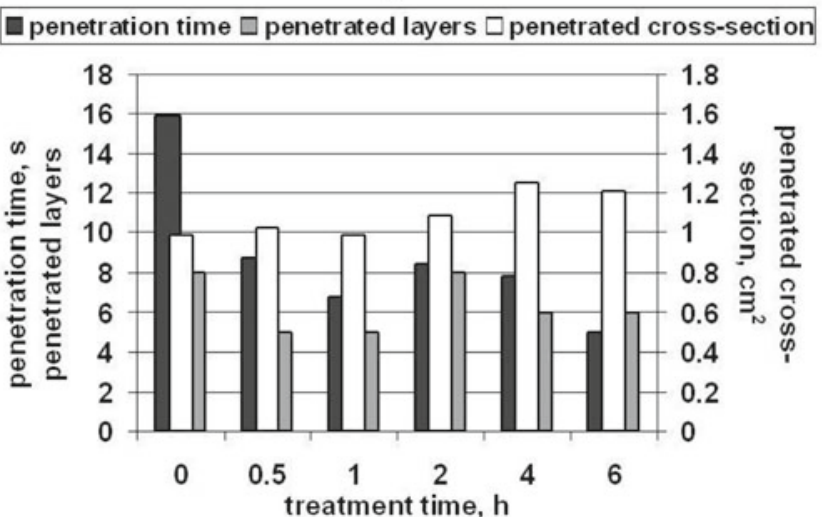

Figure 4. Change of the area of the penetrated part of specimen's cross section, the penetration time and the number of layers wetted by the penetrating resin for various treatment duration in: a) $5 \% \mathrm{NaOH}$, b) $5 \% \mathrm{KOH}$

resin for various treatment duration in: a) $5 \% \mathrm{NaOH}$, b) $5 \% \mathrm{KOH}$, are presented.

The results indicate that $\mathrm{KOH}$ solution has a stronger affect on the fabric in comparison with the $\mathrm{NaOH}$ - after $\mathrm{KOH}$ treatment comparable absorbability $(\mathrm{m}=5.39 \mathrm{~g})$ was obtained after shorter duration in comparison with the $\mathrm{NaOH}$ one $(5 \% \mathrm{KOH} 1 \mathrm{~h} \Leftrightarrow 5 \% \mathrm{NaOH} 2 \mathrm{~h})$. The low-concentrated treatments do not cause a significant degradation in the fabric structure and mechanical properties, what has already been revealed in previous researches ${ }^{4,7,8,10}$.

The effect of concentration of $\mathrm{NaOH}$ and $\mathrm{KOH}$ water solutions on treatment duration ensuring the biggest mass of the absorbed resin (absorbability) on the mass of the absorbed resin itself is presented in Fig.5.

During the treatment process the duration for which the fabric shows the biggest absorbability may be established. It was observed that the higher concentration of the solution the shorter treatment duration necessary for obtaining the best absorbability. Fig.6 presents the results of the effect of treatment in the organic compounds: vinyl acetate, methanol, toluene diizocyanate on the area of the penetrated part of specimen's cross section, the penetration time, number of layers wetted by penetrating resin and the mass of absorbed resin (absorbability).

Treatment in the organic compounds gives improvement in the infiltration of the resin into fabric structure. The best results were obtained for methanol. The improvement in the absorbability of the fibres was probably the a)

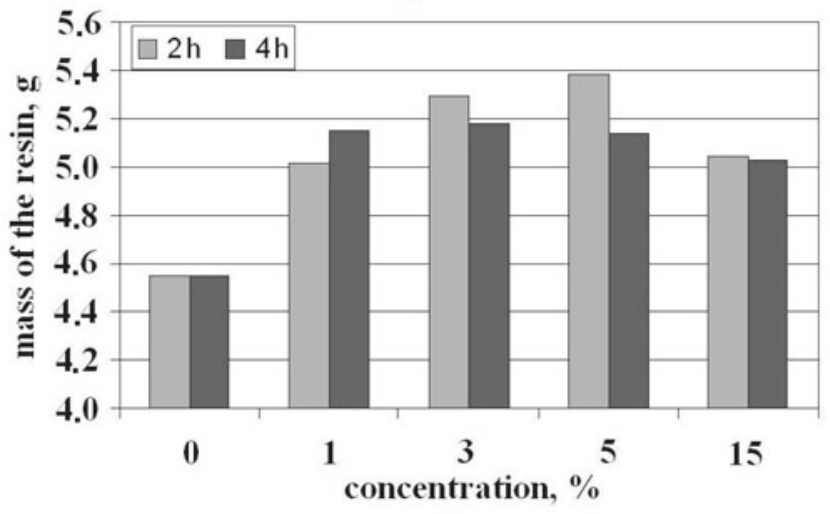

b)

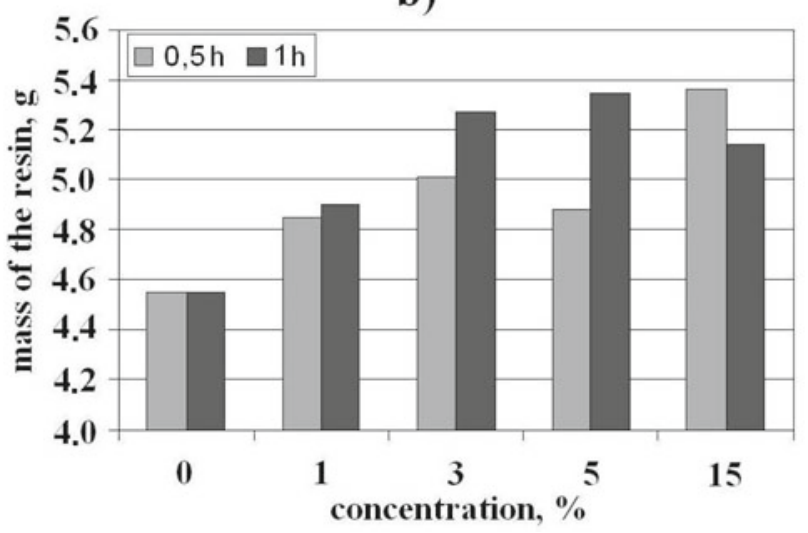

Figure 5. The effect of the concentration of $\mathrm{NaOH}$ (a) and $\mathrm{KOH}$ (b) water solutions on the mass of the absorbed resin (absorbability)

result of change in a cellulose structure throughout reaction of methyl groups with $\mathrm{OH}$ - groups belonging to the cellulose chains ${ }^{1,2}$. Application of toluene diizocyanate and vinyl acetate significantly shortens the penetration time in comparison with untreated fibres. However, it does not give satisfactory absorbability. After treatment in vinyl acetate it increases only by $1,76 \%$, while toluene diizocyanate simply causes a decrease in the jute fibres absorbability with the polyester resin.

Application of the chemical treatment causes 20-50\% increase in the area of the penetrated part of the specimen's cross section. For instance, for the treatment in $5 \% \mathrm{KOH} 1 \mathrm{~h}$ the saturated area increased by about $50 \%$ when compared with the untreated jute. The change of the mechanism of resin penetration into the fabric stack was also observed. For the untreated jute fabric the resin penetrates in the direction perpendicularly to the upper surface of the stack, resulting during the test in a bigger number of the wetted layers (Fig.7a). After the treatment in $5 \% \mathrm{KOH}$ the number of the wetted layers was lesser, but the resin propagated along the layers (Fig.7b).

Other authors recommend the duration as the main criteria of the treatment as a rule ${ }^{\mathbf{1 0 - 1 2}}$. The type and concentration of the acting chemicals are usually established beforehand on the base of initial considerations. In some cases the process temperature is taken as the criteria but in most cases it is the precisely established process parameter or it tends to reduce due to technology economics. However, all the process parameters affect directly or indirectly the treatment processes 
a)

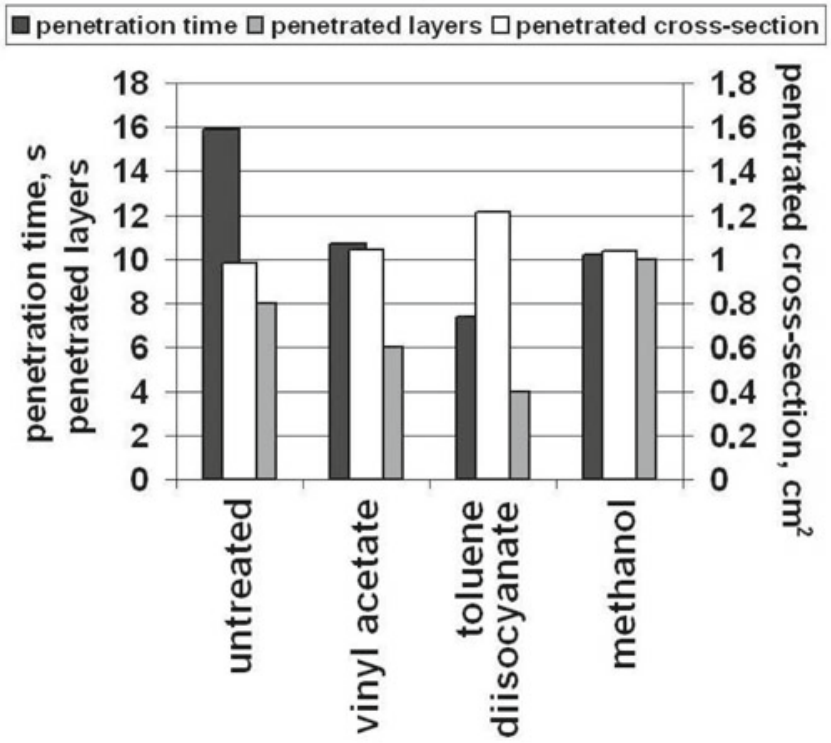

b)

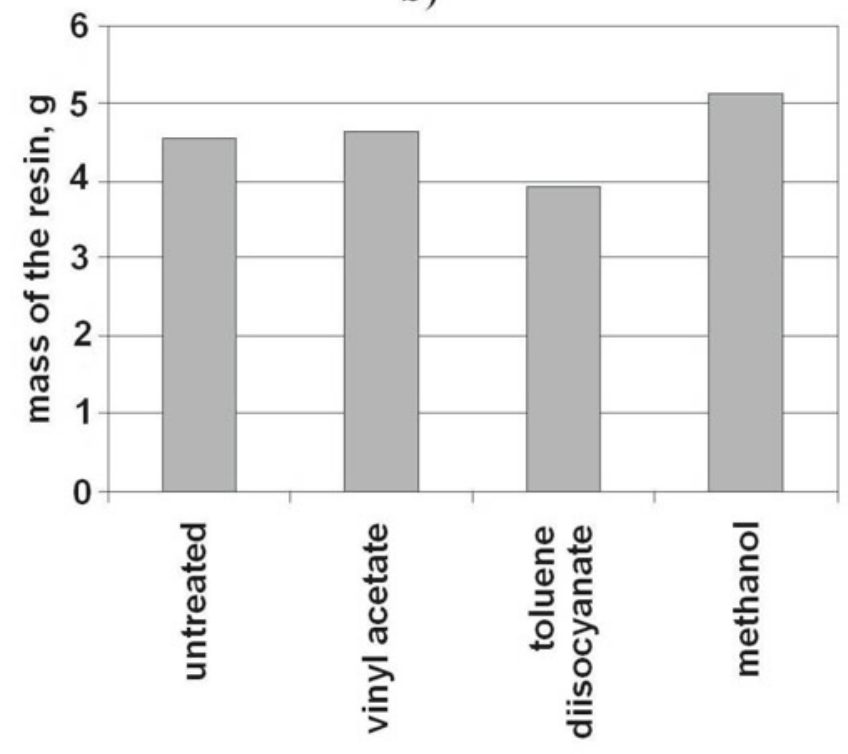

Figure 6. Change of the area of the penetrated part of specimen's cross section, the penetration time and the number of layers wetted by the penetrating resin (a) and the mass of the absorbed resin (absorbability) in the organic treatments (b)
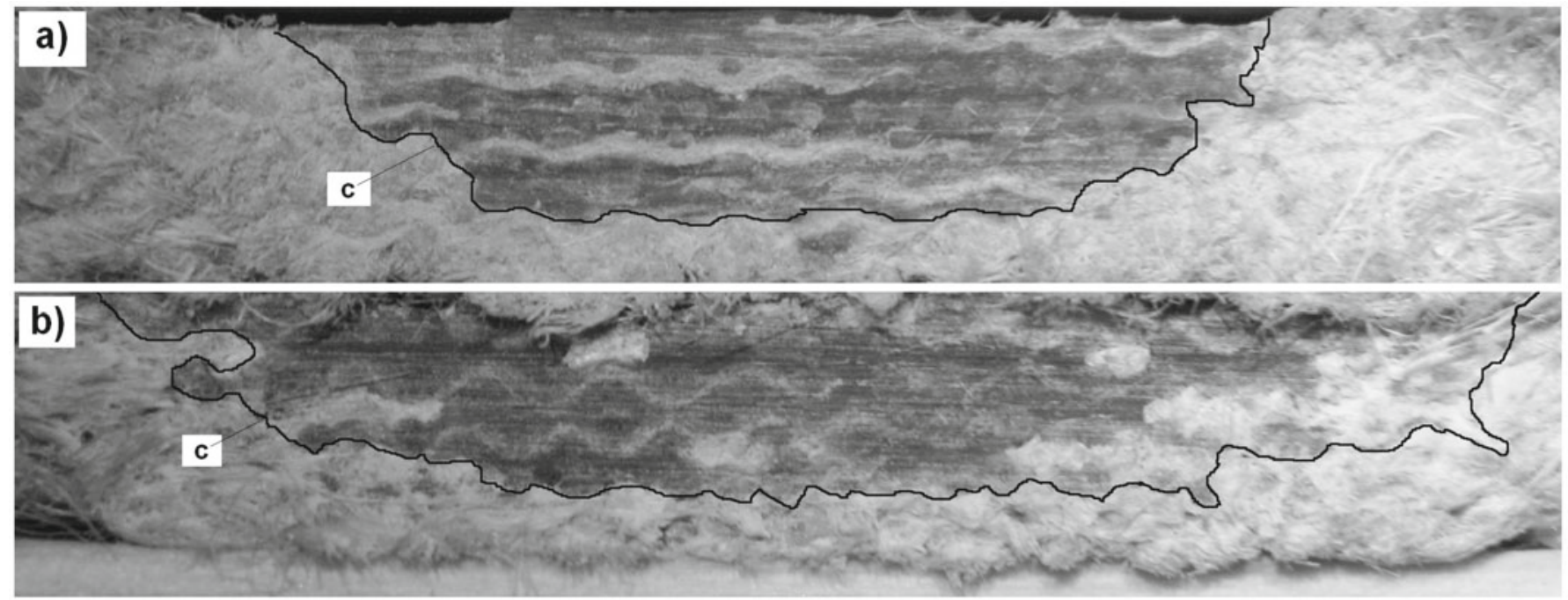

Figure 7. The contour (c) of the penetrated area of specimen's cross section: a) untreated jute fabric, b) jute fabric after the treatment with $5 \% \mathrm{KOH} 1 \mathrm{~h}$

effectiveness ${ }^{\mathbf{1 3}}$.

The solution concentration and the treatment time were taken as the alkali-treatment criteria within the study. Depending on these parameters different changes in fibres structure occurred. For instance, depending on the concentration, removal of the lignin (lower concentration) or hemicellulose (higher concentration - 5\% and more) from the fibre structure may occur ${ }^{14}$. It results in bonds loosening ${ }^{\mathbf{1 5}}$ and microfibrils rearrangement ${ }^{\mathbf{1 5}, \mathbf{1 6}}$. Simultaneously, transformation of primary cellulose into type II cellulose may proceed with additional structure arrangement in fibrils near-surface areas ${ }^{\mathbf{1 0}}$. In former researches the authors found that the modifications of the cellulose structure with alkalis and some organic substances as well cause improvement in its compatibility with other chemical substances as polyester and epoxy resins or even natural-origin compounds having cellulose-like structure ${ }^{\mathbf{8 , 1 7}}$.

Depending on the treatment time, some processes may increase their intensity and some may be activated only after longer treatment duration ${ }^{\mathbf{5 , 6}}$. The instance of treatment time affecting the treatment effects may be the researches in which jute fibres were chemically treated with $5 \%$ solution of $\mathrm{NaOH}$ for 2, 4 and $8 \mathrm{~h}$. The chemical analysis, FT-IR studies and SEM observations revealed that hemicellulose and lignin removed after alkali treatment and rough surface morphology of treated fibre occured. Additionally, SAXS analysis results suggest the swelling behaviour of the cellulose in the fibre. Swelling is found maximum at $2 \mathrm{~h}$ alkali treatment. This may be due to the heavy dissolution of the hemicelluloses at this treatment time. The microstructure analysis of fibre by XRD revealed that the degree of crystallinity increased significantly after alkali treatment longer than 2 hours. This could be due to the removal of noncrystalline structural components out of the cell wall of the fibre, leading to the closer packing of cellulose chain resulting improved mechanical strength ${ }^{5}$.

An example of researches concerning a wide spectrum of treatment process conditions on its effectiveness may be the chemical modification of cellulosic fibers with a fatty acid coupling agents. Within the researches oleoyl 
chloride has been used as a coupling agent to turn the hydrophilic surface of jute fibers into hydrophobic, leaving an olefinic residue able to react with the matrix. The esterification of hydroxyl groups during the modification reaction has been evidenced by FTIR spectroscopy, which established the development of ester bonds between hydroxyl groups of cellulose fiber and the coupling agent. The results confirmed higher modification degrees using pyridine as a solvent medium (accessibility of hydroxyl groups was improved). It was assessed that the efficiency of the reaction depends on the solvent polarity and his catalytic capacity, which are two factors governing the extension of the modification reaction. Other factors such as temperature, treatment time, the amount of the coupling agent, volume ratio and catalyst contribute to the increase in the modification degree ${ }^{13}$.

Comparing the results obtained for the treatment with the organic substances and the treatment with $\mathrm{NaOH}$ and $\mathrm{KOH}$ water solutions, it was found that the alkalitreatment has much more advantageous effect on resin - jute fabric infiltration processes. Among the organic compounds, methanol showed the best results, but they were worse in comparison with those of alkali-solutions. Specimens of the jute fabric treated with $\mathrm{NaOH}$ and $\mathrm{KOH}$ solutions reveal better absorbability and bigger saturated part of specimen's cross section (average increase by $40 \%$ ) when compared with the fabric treated with methanol. It may contribute to shortening and facilitating the composite manufacturing process.

The initial mechanical tests (static tensile, static bending, Charpy's impact resistance) made on equivalent specimens of the composites manufactured on the base of untreated jute fabric and jute fabric after various treatments showed that alkali- and organic treatments significantly improve their mechanical performance (Table 1).

Table 1. Analytically measured parameters of biowaste (average values)

\begin{tabular}{|l|c|c|c|}
\hline $\begin{array}{l}\text { Treatment } \\
\text { type }\end{array}$ & $\begin{array}{c}\text { Improvement } \\
\text { in tensile } \\
\text { strength, } \%\end{array}$ & $\begin{array}{c}\text { Improvement } \\
\text { in flexural } \\
\text { strength, \% }\end{array}$ & $\begin{array}{c}\text { Improvement in } \\
\text { Charpy's impact } \\
\text { resistance, \% }\end{array}$ \\
\hline $1 \% \mathrm{NaOH} 6 \mathrm{~h}$ & 28 & 29 & 64 \\
\hline $1 \% \mathrm{KOH} 4 \mathrm{~h}$ & 8 & 7 & 50 \\
\hline $5 \% \mathrm{KOH} 1 \mathrm{~h}$ & -5 & -6 & 33 \\
\hline $\begin{array}{l}15 \% \mathrm{KOH} \\
0,5 \mathrm{~h}\end{array}$ & -41 & -21 & -48 \\
\hline methanol & 89 & 78 & 129 \\
\hline $\begin{array}{l}\text { toluene } \\
\text { diisocyanate }\end{array}$ & 34 & 38 & 117 \\
\hline
\end{tabular}

The obtained mechanical results do not correspond strictly with adhesive behavior investigated within the study: the organic treatments (methanol, toluene diisocyanate) give better improvement in mechanical properties in comparison with the alkali-treatments (which revealed better ability to be wetted by the resin). Some additional deterioration (stiffening, making more brittle) of the fibre structure may be a probable reason. However, the relation between the fibres structure and mechanical properties of the composites is a subject of further studies.

\section{CONCLUSIONS}

The conducted investigations on the effect of chemical treatment of jute fabric on its wetting with polyester resin showed that it is possible to determine the type and parameters of the treatment, giving improvement in technological properties of the fabric.

Regarding the assumed criteria (basic criteria of infiltration quality): time of penetration of the resin into the reinforcing fabric, fabric absorbability and the part of the area of the specimen cross-section penetrated with the resin treatment conditions providing the best resin absorption (the biggest mass of absorbed resin) were determined. In the required conditions the best results were shown by the fabrics treated with $1-5 \%$ by long-time, $15 \%$ by short-time $\mathrm{NaOH}$ and $\mathrm{KOH}$ water solutions. Good effects were also obtained after the treatment with methanol, but absorption parameters were worse in comparison with the alkali-treatment. These results do not correspond directly with the mechanical properties of the cured composites manufactured on the base of the treated fabrics. Alkali- and organic treatments significantly improve the mechanical performance of natural fibres reinforced composites. However, organic treatment (methanol, toluene disocyanate) gave better improvement in the mechanical properties in comparison with alkali-treatments.

Measurement methods applied within a framework of the study may be generally useful in an evaluation of the effect of chemical treatment of natural fibres on their wettability with liquid matrix.

\section{ACKNOWLEDGEMENTS}

This work is partially financed by the Ministry of Science and Higher Education of the Republic of Poland within the scope of the N N508 440936 project.

\section{LITERATURE CITED}

1. Bledzki, A. \& Gassan, J. (1999), Composites reinforced with cellulose fibres, Prog. Polymers. Sci., 24, 221-274

2. Khan, F. \& Ahmad, S.R., (1996), Chemical modification and spectroscopic analysis of jute fibre, Pol. Degr. and Satab., 52, 335-340.

3. Kalia, S., Kaith, B.S. \& Kaur, I., (2009), Pretreatments of natural fibers and their application as reinforcing material in polimer composites: a review, Pol. Eng. and Sci., 49, 1253-1272, DOI: $10.1002 /$ pen.21328.

4. Sticchi, A. \& Lauke, B., (2007), A novel fiber treatment applied to woven jute fabric/ vintlester laminates, Comp.: Part A, 38, 1337-1343, DOI: 10.1016/j.compositesa.2006.10.010.

5. Pietak. A., Korte. S., Tan. E., Downard. A. \& Staiger. M.P., (2007), Atomic force microscopy characterization of the surface wettability of natural fibres, Appl. Surf. Sci., 253, 3627-3635, DOI: 10.1016/j.apsusc.2006.07.082.

6. Sinha, E., Rout, S.K., (2009), Influence of fibre-surface treatment on structural, thermal and mechanical properties of jute fibre and its composite, Bull. Mater. Sci., 1, 65-76.

7. van de Weyenberg, I., Chitruong, T., Vangrimde, B. \& Verpoest, I., (2006), Improving the properties of UD flax fibre reinforced composites by applying an alkaline fibre treatment, Comp.: Part A, 37, 1368-1376, DOI: 10.1016/j. compositesa.2005.08.016.

8. Qin, C., Soykeabkaew, N., Xiuyuan, N. \& Pejs, T., (2008), The effect of fiber volume fraction and mercerization on the properties of all - cellulose composites, Carboh. Pol., 71, 458-467, DOI: 10.1016/j.carbpol.2007.06.019. 
9. Gassan, J., (1997), Natural fiber-reinforced plastics - Correlation between structure and properties of the fibers and the resultat composites, Unpublished doctoral dissertation, University of Kassel, Kassel, Germany.

10. Manisikkamaki, P., Lahtinen, M. \& Rissanen, K., (2007), The conversion from cellulose I to cellulose II In $\mathrm{NaOH}$ mercerization performer in alcohol water system: X - Ray powder diffraction study, Carboh. Pol., 68, 35-43, DOI: 10.1016/j. carbpol.2006.07.010.

11. Podgorski, L., Chevet, B., Onic, L. \& Merlin, A.H., (2000), Modification of wood wettability by plasma and corona treatments, Int. Jour. of Adh. \& Adh., 20, 103-111.

12. Topalovic, T., Nierstrasz, V.A., Bautista, L., Jocic, D., Navarro, A., Warmoeskerken, M.M.C.G., (2007), XPS and contact angle study of cotton surface oxidation by catalytic bleaching, Coll. and Sur. A: Phys. Eng. Asp., 296, 76-85, DOI: 10.1016/j.colsurfa.2006.09.026.

13. Corrales, F., Vilaseca, F., Llop, M., Girones, J., Mendez, J. A., Mutj, P., (2007), Chemical modification of jute fibers for the production of green-composites, J. of Haz. Mat., 144, 730-735, DOI: 10.1016/j.jhazmat.2007.01.103.

14. Karmakar, S.R. (1999), Chemical technology in the pretreatment processes of textiles, Elsevier Science \& Technology, Netherlands.

15. Ray, D., Das, M. \& Mitra, D. (2009), Influence of alkali - treatment on creep properties and crystallity of jute fibers, Bioresources, 4, 730-739.

16. Gassan, J. \& Bledzki, A., (1999), Alkali treatment of jute fibers: relationship between structure and mechanical properties, J. of Appl. Pol. Sci., 71, 623-629.

17. Mwaikambo, L.Y. \& Ansell, M.P., (1999), The effect of chemical treatment on the properties of hemp, sisal, jute and kapok fibers for composite reinforcement, $2^{\text {nd }}$ International Wood and Natural Fibre Composites Symposium, 28-29 June 1999 (pp. 41-46). Kassel, Germany. 